\title{
Social-Relational Understandings of Health and Well- Being from an Indigenous Perspective
}

REVISED REFERENCES, 04/13/2016

\begin{abstract}
This article presents the findings from a research project that examined how well-being, especially with regard to diabetes prevention, was understood within an Indigenous community, Kahnawà:ke, a Kanien'kehá:ka community on the St. Lawrence River near Montreal, Quebec, Canada. Both philosophical hermeneutics and Indigenous ways of knowing were used to achieve a decolonized research approach to undertaking and analysing interviews from key stakeholders. The research findings revealed that the social- conditions created by external Western influences on culture, language, and epistemologies are strongly connected to the relational conditions that continue to influence the health and well-being of individuals, families, and the community. Indigenous well-being was found to be closely related to the concept of being Onkwehon:we, to the roles and responsibilities of families as nurturers of health-promoting relationships, and to processes expected to promote the healing of multigenerational traumas rooted in a history of colonization. Developing a shared understanding of Indigenous people's knowledge about what is required to effectively prevent type 2 diabetes, while simultaneously fostering the sense of being Onkwehon:we, is a new approach to health promotion within Indigenous communities.
\end{abstract}

\section{Keywords}

Multigenerational traumas, Indigenous ways of knowing, philosophical hermeneutics, colonization, social-relational, type 2 diabetes prevention, health and well-being

\section{Glossary}

Haudenosaunee: People of the Longhouse, or the Six Nations Iroquois Confederacy.

Kanien'kehá:ka: The Kanien'kehá:ka, or People of the Flint, are more commonly referred to as Mohawks, a name imposed upon the people.

O:henton Kariwatehkwen: "the words that come before all else, or Thanksgiving Address" that the Haudenosaunee traditionally speak at sunrise and sunset, and at the opening and closing of any official gathering.

\section{Authors}

Richard Hovey, PhD, Associate Professor, Division of Oral Health and Society, Faculty of Dentistry, McGill University \& Research Team Member, Kahnawake Schools Diabetes Prevention Project (Kahnawake, QC Canada). Richard Hovey was the primary investigator and lead qualitative researcher. It was this expertise that guided the data collection, analysis, and article development. 
Social-Relational Understandings of Health and Well-Being from an Indigenous Perspective $\bullet$ Richard B Hovey, Treena Delormier, Alex McComber

Treena Delormier, PhD, Assistant Professor Office of Public Health Studies Native Hawaiian and Indigenous Health, University of Hawaii at Manoa (Oahu) \& Research Team and Community Advisory Board Member, Kahnawake Schools Diabetes Prevention Project (Kahnawake, QC Canada). Treena Delormier was a co-primary investigator, involved in all aspects of data collection, analysis, and article development.

Alex M McComber, M.Ed., Kahnawake Schools Diabetes Prevention Project (KSDPP) Community Researcher \& Community Advisory Board member \& Adjunct Professor Faculty of Education, Department of Integrated Studies in Integration, McGill University \& former teacher and principal with the Kahnawake Survival School. Otsehtokon Alex M. McComber M.Ed. is Bear clan from Kahnawake Territory. Alex M McComber was a co-primary investigator, involved in data analysis, and article development.

\section{Acknowledgments}

We would like to thank the following persons for their review and feedback of this article for Indigenous content. Morgan Phillips, MA Anthropology / PhD Student McGill University, Montreal QC. Canada. Geraldine Standup, community Elder, Kahnawake, QC, Canada. Gerald Taiaiake Alfred, PhD, Director of the Indigenous Governance Program, University of Victoria, BC Canada. Philip Deering, PhD student and KSDPP Community Advisory Board, Kahnawake, QC Canada. KSDPP Community Advisory Board members Joyce Rice, Terry Young, Lisa Peterson, Kahnawake, QC Canada.

\section{Introduction}

\section{Diabetes within an Indigenous Context}

In 1985, the high prevalence of type 2 diabetes was recognized as a community health issue within Kahnawà:ke (by the rapids), a Kanien'kehá:ka (People of the Flint) community on the St. Lawrence River near Montreal, Quebec, Canada, with local rates of $12 \%$ to $15 \%$ in comparison with Canadian national levels of 5\% to 6\% (Macaulay, Montour, \& Adelson, 1988; Montour \& Macaulay, 1985). In 1994, these statistics mobilized the community to create the Kahnawà:ke Schools Diabetes Prevention Project or KSDPP (Bisset, Cargo, Delormier, Macaulay, \& Potvin, 2004; Horn et al., 2007). KSDPP is a community-based, primary prevention, participatory research project focusing on the prevention of diabetes among children and future generations through enabling healthy lifestyles for youth, and through multilevel interventions that address personal choices, as well as family and school environments (Macaulay, et al., 1999). The mandate of the KSDPP is to develop and implement innovative research and intervention activities that emphasize Indigenous methodologies and research perspectives with a foundation of Indigenous philosophies and world view. As more health promotion resources were directed toward diabetes prevention within the community, more questions were raised about how stakeholders interpreted and understood diabetes, its prevention, and its effects upon Indigenous health and well-being.

The idea to investigate community stakeholders' understandings of diabetes prevention was raised and discussed at both regular KSDPP research team meetings, and by the KSDPP Community Advisory Board. This is the expected protocol for all KSDPP research (Macaulay et al., 1997). Three researchers, two who are longstanding members of Kahnawake and the KSDPP, and the third a collaborating researcher invited to be part of KSDPP's research team, designed 
Social-Relational Understandings of Health and Well-Being from an Indigenous Perspective $\bullet$ Richard B Hovey, Treena Delormier, Alex McComber

the study, gathered and interpreted the interview information and reported progress and findings to the community. Each of the researchers brought many years of experience from communityengaged, health and education work and service, and diverse research experiences. Their extensive knowledge of community history, relationships and day-to-day life, along with their commitment to creating knowledge respectfully, provided the focus for their distinct but complementary analytic perspectives. Over the course of the two year project (2010-2012) each dedicated their efforts toward creating a shared understanding of what diabetes, and its prevention, meant to frontline workers and stakeholders who work to promote well-being for Kahnawà:kehró:non (the people who live in Kahnawà:ke).

Well-being is a multifaceted, complex interaction involving many dimensions of health. It encompasses not only biomedical markers but also unique life circumstances that individuals, families, and communities experience in their day-to-day existence (Struthers, Schanche Hodge, Geishirt-Cantrell, \& De Cora, 2003). Well-being can then be interpreted through essential interconnections in the multiple dimensions of health, including but not limited to: spiritual, social, relational, intellectual, cultural, mental, emotional, environmental, and occupational (Donatelle \& Thompson, 2012; Hovey \& Craig, 2011; Hovey, 2012; Willows, Hanley, \& Delormier, 2012). Both Indigenous and non-Indigenous scholars have begun to question whether illnesses such as diabetes may be in part symptomatic of oppressive social conditions (Alfred, 2009a; Brass, 2009; Hart, 2010; King, Smith, \& Gracey, 2009; Kulnieks, Longboat, \& Young, 2010; Wilson, 2008). This has led the researchers to interpretively (hermeneutically) conceptualize the conditions that influence the health and well-being of this Indigenous community. Philosophical hermeneutics was chosen as a research approach as it aligns with an Indigenous centred approach in the interpretive relationship shared among the tricksters - Coyote, Raven, and Hermes. All of these tricksters spoke messages that must be interpreted in order to gain an understanding of their intended communication.

Well-established risk factors for diabetes, such as obesity, physical inactivity, and unhealthy eating habits, are closely related to the social-relational circumstances of individuals (Dow, 2006; Haskell \& Randall, 2009; Metallic, 2004; Travers, 1995). Recognizing that diabetes may be an expression of the social-relational well-being of a community (Hovey, 2012) has created a necessity to further explore these considerations. The present research study represents a community-driven evolution towards an approach to research that is Indigenous-centred in both perspective and philosophy.

\section{Social-Relational Connections to Diabetes Prevention}

Within the context of the social-relational interconnection, social interactions reveal how the internal social structure of an Indigenous community can be impacted by dominant external social structures and practices. The relational aspect pertains to the human relationships that connect the individual, family, and community. According to Wilson (2008), “...the relational way of being was at the heart of what it means to be Indigenous" (p. 80). The relational aspect of the Indigenous worldview does not apply only to human relationships; it also encompasses the relationship to the land, the environment, the cosmos, and ideas (Wilson, 2008). Interpreted through a Haudenosaunee (People of the Longhouse) perspective, the O:henton Kariwatehkwen (the words that come before all else) embodies these wider relationships (King, 2007). It is traditionally spoken or recited at sunrise and sunset, or at the opening and closing of ceremonies, meetings or other formal gatherings. O:henton Kariwatehkwen reminds the people to be appreciative of the circle of life and the interconnected relationships of Mother Earth and the Universe. It acknowledges that human beings are part of an intricate interrelationship with all 
Social-Relational Understandings of Health and Well-Being from an Indigenous Perspective $\bullet$ Richard B Hovey, Treena Delormier, Alex McComber

those things that collectively ensure a continuity of life and good health: the earth, the waters, all living creatures, all things that grow, and spiritual relatives, as represented by the thunders, winds, sun, moon and stars, spiritual ancestors, and creator (King, 2007).

Current social-relational interactions, culture, as well as interpersonal and other relationships continue to be distorted by the tension created between the co-existing influences of Haudenosaunee and Kanien'kehá:ka traditional world views, values, and cultural practices, and the devastating influence of European colonization and Canadian governmental oppression. While the negative consequences of colonization on the lives of Indigenous Peoples have been powerfully characterized, insights into the current social-relational context of well-being and its implications have not, and this merits further exploration.

Our original research project was intended to focus on how community health practitioners expressed their beliefs about the efficacy of current diabetes prevention activities in Kahnawà:ke. An initial exploration through personal interviews led the researchers to investigate a new dimension: the complex social-relational conditions that influence well-being in Kahnawà:ke. The resulting knowledge, and the perspective on Indigenous well-being that arose from it, created a new hermeneutic space to inform innovative research approaches that recognize how transforming social-relational conditions holds promise for enhancing the lives and well-being of Kahnawà:kehró:non. The hermeneutic research conversation must occur in a space where mutual openness and generosity abound. This is akin to what Ermine, Sinclair, and Jeffery (2004) referred to as "ethical space" within the sometimes-precarious relationship between Indigenous Peoples and researchers.

This in turn led us to pursue a deeper understanding of the impact of colonization experienced within contemporary Kahnawà:ke. Throughout this article we articulate how the interplay of self, family, and community within social-relational conditions affected the efficacy of diabetes prevention activities both in practice and by establishing the context within which the activities are conducted, and hence came to be at the forefront of our research.

\section{The Community}

Kahnawà:ke is the furthermost north-eastern Kanien'kehá:ka community of the Haudenosaunee. Established in 1716, present day Kahnawà:ke is situated on the south shore of the St. Lawrence River, 15 kilometres from downtown Montreal. The region is part of the northern territory of the Kanien'kehá:ka, who had previous settlements in the area. The site lies to the west of an earlier settlement, that had been founded in 1680 as a Christian mission and was populated by Christian-converted peoples from several Indigenous nations in the St. Lawrence River region, of which the Kanien'kehá:ka were the most numerous. The King of France recognized the area as the Seigneurie de Sault St. Louis in 1680 (Blanchard, 1980). In spite of being situated within a community that was at one time predominantly Christian, the Kahnawà:kehró:non continue to engage with the values, culture, traditions, and ceremonies of the Haudenosaunee, which survive and are still practised today.

\section{Colonization Experiences and Indigenous Communities}

The disastrous impacts of colonization upon the lives of multiple generations of Indigenous Peoples in Canada are recognized and well documented (Alfred, 2009b; King et al., 2009; Royal Commission on Aboriginal Peoples (RCAP), 1996). Colonization dispossessed Indigenous Peoples of their lands, languages, social structures, modes of self-governance, customs, and cultural practices with profound effects on social-relational interactions. 
Social-Relational Understandings of Health and Well-Being from an Indigenous Perspective $\bullet$ Richard B Hovey, Treena Delormier, Alex McComber

The introduction of new illnesses to these Indigenous populations compounded the devastation wrought by the effects of colonization. For example, European settlers coming to North America introduced smallpox and other diseases that quickly decimated Indigenous families and communities. Indigenous people lacked immunity to these new diseases. Where traditional medicines were not effective against them, many community members died (RCAP, 1996). Survivors were left to care for the seriously ill and disabled while endeavouring to mend the social fabric, or create a new one, under traumatic social and health conditions. European missionaries saw an opportunity to convert the population in large numbers, decrying the paganism of ancient religion as the cause of the illnesses and deaths, and introducing JudeoChristian values as the path to both physical and spiritual salvation (Milloy, 1999).

The primary goal of colonization was to dispossess Indigenous Peoples from their homelands and territories and to subjugate their collective Indigenous existence. The explicit purposes of this process were to claim territories for colonial empires, and appropriate prime lands and locations for colonial settlement and economic exploitation. The impacts of colonization had, and continue to have, cataclysmic effects on the economic and social dimensions of Indigenous Peoples' lives (Alfred, 2009a). Traditional food systems were transformed by land dispossession and new economic and trade relationships. Introduced commodities such as alcohol, salt, sugar, lard, and flour resulted in negative nutritional and health impacts for generations (Mundel \& Chapman, 2010). The legacy of European colonization continued unabated upon Canadian Confederation in 1867, with the enactment of laws such as the Indian Act. These led to the implementation of policies governing Indigenous identity, to forced schooling, and to contentious land claims processes, and created, in no small part, the current contexts of Indigenous Peoples' lives. From the perspective of Indigenous Peoples, the cumulative and ongoing effects of colonization severely limit opportunities to live self-sufficient, healthy, and autonomous lives (Adelson, 2005; Alfred 2009a). As Kirmayer and Valaskakis (2009) stated, "When one considers the material consequences of Canada's century-long policy of state-sponsored forcible assimilation, a simple fact emerges: for generations, opportunities to live well as an Aboriginal person have been actively frustrated" (p. xi). Colonization, with its accompanying assimilationist legislation and genocidal attitudes on the part of government, inflicted upheaval and trauma on the Indigenous population, leading to adverse effects in the social, mental, emotional, and physical dimensions of health (Hovey, 2012).

\section{Methods}

\section{Social-Relational Perspectives and Decolonized Research}

This Hermeneutic research project required the researchers to deeply engage narrative data from the perspective that the social and the relational hold unique meanings for Indigenous People, distinct from Eurocentric (Western) perceptions, understandings, and interpretations. In order to proceed through a decolonized analysis of the data, we needed to ground our research approach upon Indigenous philosophies, concepts, and worldviews. In this regard, the "relational is central to Indigenous ways of knowing and acting" (Wulff, 2010, p. 1290). Wilson (2008) adds that "reality is not an object but a process of relationships, and an Indigenous ontology is actually the equivalent of an Indigenous epistemology" (p. 73). Philosophical hermeneutics, a recognized decolonized means of achieving understanding (Davey, 2006), and a research approach not previously used in Kahnawà:ke, provided a methodological bridge on which to situate our research. This approach acknowledges the significance of Indigenous perspectives 
Social-Relational Understandings of Health and Well-Being from an Indigenous Perspective $\bullet$ Richard B Hovey, Treena Delormier, Alex McComber

and facilitates the development of Indigenous theory and methods of practice (Wilson, 2008). The tenets of a decolonized approach to research exemplify how traditional sharing of beliefs, values, and customs can inform and guide research that follows appropriate codes of conduct and that honours Indigenous systems of knowledge and world views (Brant-Castellano, 2004; Ermine, 2007; Kovach, 2009; Phillips, 2010; Smith, 1999; West, Stewart, Foster, \& Usher, 2012; Wilson, 2008).

McGuire (2010) pointed out that, "knowledge theories are developed by people within a social context participating in their social worlds. Indigenous theories can be developed, that offer a mirror in which Indigenous Peoples see themselves reflected back" (p. 127). Furthermore, we as authors recognize that Indigenous theories exist and can be drawn upon through a research process that views diverse perspectives, in this case Indigenous perspectives, as valid. In this sense, studying the perceptions of social-relational contexts and the lived realities developed by people participating in their social worlds requires specific attention to and analysis of a relevant research approach and the nature of the data it generates. At the study's outset, it was important for the researchers to ensure that conversations with community members would be steeped in a different theoretical and methodological tradition, departing from the understandings of health that underpin the biomedical, preventive, and program-based intervention approaches (Hovey \& Paul, 2007; Kulnieks et al., 2010; Thomas, 2003, 2004). It is also important to acknowledge that knowledge development occurs within wider social and political contexts. These unique Indigenous social circumstances define who Indigenous people are: "This social frame of being Aboriginal creates a particular way of viewing, understanding, and critiquing social surroundings" (McGuire, 2010, p. 127). According to Alfred (2005), the identity of Aboriginal is a "legal and social construction of the state, which is disciplined by radicalized violence and economic oppression to serve the agenda of silent surrender" (p. 23).

The term social-relational that we are presenting is hyphenated to emphasize the meaning of the social-with the -relational, where the social- has an explicit influence on the relational. Perspectives on relationships differ between Indigenous and non-Indigenous Peoples, and "rather than viewing ourselves as being in relationships with other people or things, we are the relationships that we hold and are part of" (Wilson, 2008, p. 80). To be consistent with the meaning of Onkwehon:we (real human beings who live in spirit), well-being can only be achieved by attending to the whole person, therefore we will use the word wholistic to express this idea of whole health as wellness. The $w$ in this variant spelling serves as an explicit reminder of wholeness. Integration of this knowledge will make explicit Indigenous perspectives about the current realities and experiences of colonization and its influences on individual and collective well-being. Specifically, we will explore social-relational conditions and how these powerful interconnections can influence well-being.

As researchers with different cultural backgrounds, education, and research methodological expertise we recognize that the integrity and rigor found in any research approach is first in its alignment with the topic. This is through an understanding that no single method can provide the answers and every method has its own strengths and weaknesses in application. We chose philosophical hermeneutics because of its utility in both philosophy and practice to gain deeper insight to a topic. We as researchers acknowledge that other methodologies may have achieved similar findings. The researchers in this study found answers to questions that were not directly asked about colonization and its effect on health and wellbeing. The initial questions asked of the participants were rather centred on how diabetes health promotion could be improved at a community level. We intend to follow-up this research with 
Social-Relational Understandings of Health and Well-Being from an Indigenous Perspective $\bullet$ Richard B Hovey, Treena Delormier, Alex McComber

another study, which will ask community members specifically about their understanding of how colonization has impacted health and wellbeing.

As a means to authenticate these findings the researchers provided drafts to several Indigenous community members who represent knowledge holders, academics, historians, and health promotion experts for their feedback. Their comments and suggestions were incorporated throughout this manuscript.

\section{Philosophical Hermeneutic Research Approach}

Philosophical hermeneutics guided by the trickster messenger Hermes, has evolved into a sophisticated research approach with its utility in uncovering deeper meanings in complex experiences. Hermeneutics was founded in the ontological understanding that the world is interpretable, and that we as humans are always in the process of interpreting the events and experiences we encounter in our lives (Gadamer, 1976, 1989, 1992; Hovey \& Amir, 2013). Furthermore, the hermeneutic philosopher Hans-Georg Gadamer does not accept the relativism of personal perspectives about an experience; this is why as researchers we seek common ground around being-in-the-world, as we cannot escape our cultural, communal, and historical context within competing interpretations of an experience (Davey, 2006). This is one of the strengths of research guided by philosophical hermeneutics in that the reflexivity of who we are and what researchers bring converges with the topic of interest in a continuing process of analysis.

In philosophical hermeneutics, interpretation is an ongoing process that begins with initial understandings of the research protocol and continues through the interview process, transcription, and textual analysis. These understandings are finally explicated through interpretive writing. This approach relies on a deep engagement with the topic and textual data, and attempts to generate new or different understandings through a circular interpretive movement from the narrative parts of the experience to the whole rather than extracting or codifying themes. The hermeneutic circle pragmatically describes the researcher's circular activity of beginning with each unique participant's experience, which is then brought into a perceptual context created with all of the other research participants.

The philosophical hermeneutic researcher moves away from a positivistic-objective understanding of research as a foundational method, to one where understanding is inclusive of the subjective and ontological uncertainty found within all human experiences. Research that aims to find objective truth and understanding within human experience will always produce a dilemma, as a result of the shifting and changing perceptions that are fundamental to the contextual nature of human experience, culture, society, and history (Gadamer, 1989; Grondin, 2003). Philosophical hermeneutics advocates that subjectivity is an avenue to greater objectivity, not an obstacle. Subjectivity in the sense of having a distinct but negotiated point of view can be regarded as enabling new and different understandings to arise (Davey, 2006, Gadamer, 1996). It is because each unique narrative is brought together with others that a common expression may be found in the "fusion of horizons" (Gadamer, 1989). This occurs through an interpretative process in which the researchers compare and contrast their various interpretations of the data.

\section{Data Collection}

Ethics approval for this project was obtained from the KSDPP Community Advisory Board (CAB) and McGill University's Internal Review Board. CAB oversees and guides KSDPP activities, including research, in Kahnawà:ke. Its goal is to ensure that cultural and community values are upheld, under the guidance of the KSDPP Code of Research Ethics. We began by identifying individuals from all programs and services whose responsibilities included 
Social-Relational Understandings of Health and Well-Being from an Indigenous Perspective $\bullet$ Richard B Hovey, Treena Delormier, Alex McComber

addressing diabetes prevention and health promotion in the community. Participants were selected from diverse occupational backgrounds and for their varying perspectives. Included were front-line community health workers, health professionals, educators, health and education administrators and decision makers, traditional healers, and community researchers. All participants except one were members of the Kahnawà:ke community. Informed consent was obtained from each participant prior to conducting interviews.

Two of the researchers conducted in-depth individual interviews with 15 participants. The hermeneutic interview is characterized by its attention to the quality of the conversation, in which the question is an invitation for the participant to engage the topic in a way that makes sense to him or her (Davey, 2006; Hovey \& Paul, 2007). The open-ended questions sought participant perspectives on effective diabetes prevention for the community, and on the conditions required to ensure that future generations could live free from diabetes. It was from these numerous perspectives that the researchers gained insight into new and different understandings of this topic. A single interview of 30 to 100 minutes was carried out with each participant. Interviews were digitally recorded and transcribed verbatim.

\section{Data Analysis}

In practical terms, data analysis required multiple sessions in which the team of three researchers reviewed and discussed participant narratives with the goal of coming to a shared understanding. The analytical responsibility of the researcher(s) and writer(s) is not about assuming interpretive authority, but to honour and give voice to the individual experience by showing how it is an instance of something that can be understood more generally. What we currently view as a Finding is always provisional to further interpretation and understanding. The degree, depth, and sophistication of understanding is enhanced through the interpretative viewpoints of multiple stakeholders, whereby interdisciplinarity is not a competition but a collaboration that sets out to find a new 'fusion of horizons' that either challenges or supports existing epistemologies and ways of knowing. This approach relies on a deep engagement with the topic and the textual data. It attempts to generate new or different understandings among the research team rather than extracting or codifying themes. The analytical work by members of the interdisciplinary research team was designed to open territorial boundaries, providing more flexibility in professional responsibilities, and to retain a focus on person-, family-, or community-centredness (Long, 2001; Pringle, Levitt, Horsburgh, Wilson, \& Whittaker, 2000). In this way, new understandings are discussed, negotiated, refined, and finally constituted as an authentic representation of the most meaningful interpretations from the research team (Binding \& Tapp, 2008; Hovey, 2006; Hovey et al., 2011). Interpretations were constructed iteratively into a textual account presented here as Findings.

\section{Findings}

Our initial analysis revealed a strong focus on social-relational conditions within the community. The research participants spoke about diabetes prevention strategies that consider medical and behavioural lifestyle modifications as well as interventionist approaches within the context of overarching social circumstances. Analysis of the narratives immediately revealed an unexpected yet foundational finding about the influence of relationships on well-being. Within these findings, the meaning of relationships are understood to operate at several interconnected levels: (a) that of being Onkwehon:we, which influences Haudenosaunee understandings of self and wholistic well-being; (b) how families function, or fail to function, as cohesive, loving, and 
Social-Relational Understandings of Health and Well-Being from an Indigenous Perspective $\bullet$ Richard B Hovey, Treena Delormier, Alex McComber

supportive extensions of the relationship to self; (c) the impact of this on multiple generations; and (d) what family relationships mean for well-being within the larger community.

We are Great Spirits; how, why are we great? The Great Spirit lives in us and that is why we're great. We don't know this stuff and so we get paranoid; we get really sick; we think we're worthless, we think all kinds of things, especially as native people in this country.... And what is required is people need to go on a spiritual journey. There's the part of a human being that is so totally ignored and that is our spiritual self; an understanding of where we come from, who we are, where we are going.

This quote from a research participant speaks to the tension of feeling separated from one's spiritual self, about not knowing who one is as Onkwehon:we, and the need to recover that sense of self as a great spirit. It also identifies the need to gain insight into how we as health researchers make sense of the historical, cultural, and social-relational conditions of human beings and how this relates to health. It provides us with an understanding that an individual's identity includes knowledge of the connection between the spiritual and the physical. This participant tells us that, although spiritual journeys for Indigenous people have been interrupted, they are neither lost nor forgotten.

Another participant shared: "Diabetes is about having rights. Diabetes prevention is about having rights; the right to having a quality of life as a human being." Serious chronic disease and its prevention are experienced individually yet are understood, as the quotation illustrates, to be related to the broader construct of having basic human rights, and to the social conditions required to live a life that is just and dignified (Horn-Miller, 2003). This view holds that diabetes should never become a defining characteristic for a human being. For example, labelling someone living with diabetes as a "diabetic," rather than "living with diabetes," may be seen as reducing that person's identity to the disease that may be interpreted by the person as dehumanizing, demeaning and offensive. For this participant, diabetes means being denied the possibility to be fully human; that is, to be Onkwehon:we. The quotation evokes the injustice of the diabetes disease burden that Indigenous people carry as a result of the social-relational upheaval of systemic oppression and assimilationist policies and practices. This view signifies a departure from a biomedical understanding toward one that acknowledges that wholistic health includes cultural and historical aspects (Ermine, Sinclair, \& Jeffery, 2004).

The understanding of what being fully human means, and how this concretely translates into affecting wholistic well-being is exemplified in the following quotation from a participating community health care provider:

[I]f you don't feel who you are, you'll be so outside of yourself and reckless and don't care. So when you feel, and you know who you are, and you can feel that things are wrong, and you pay attention, you're at peace because people who are stressed will start taking to cigarettes, taking to alcohol, taking to food, or any kind of reckless behaviour. So when they're calm, they're content, and they're feeling at peace, they're going to want to feed their spirit healthy foods, you know? And when I do my conferences, I make sure that they know that the foods that they eat will affect their emotions; will affect their spirit, who they are.

In other words, not being at peace, being disconnected from one's sense of self and identity, promotes risky behaviours. The quotation describes some of the negative behaviours associated 
Social-Relational Understandings of Health and Well-Being from an Indigenous Perspective $\cdot$ Richard B Hovey, Treena Delormier, Alex McComber

with low self-esteem and self-efficacy. It also speaks to one's own capacity to understand that one has the power to know and feel who one is enough to care for oneself. Connecting with one's peaceful inner spirit promotes health and well-being, which underpins our understanding that physical, emotional, behavioural, and spiritual selves are connected and interrelated. As Onkwehon:we, it is understood that the Great Spirit is within the individual, residing in minds of Onkwehon:we ; understanding this offers the possibility of personal empowerment for people on their own journey to achieve being fully Onkwehon:we. The challenge for health practitioners and the community more broadly lies in creating conditions that will enable people to follow their journeys of self-discovery and identity. This is often made difficult by constraining socialrelational conditions that frustrate attempts by Indigenous people to be Onkwehon:we.

\section{Family Expressions of the Social-Relational}

Wilson (2008) and Kovach (2009) describe family relationships as the context for key social interactions that impact well-being. From our conversations with participants, we gained an appreciation of their understandings of the role that the extended family plays in creating nurturing relationships, and in creating the socially structured roots of the dysfunctional family relationships within which they are called to intervene. As one Indigenous health care provider explained:

Then you might come into a family that has multigenerational problems, maybe their parents went to residential schools and they've been abusive to their kids and that just transmits throughout their generations, and we might see multigenerational families just keep coming through the doors and never really getting out of that hole.

This participant provides an example from the residential school experience where Indigenous children were forcibly taken from families and communities to erase their connection to their culture, language, and traditions. As more information about these residential schools has emerged, some of the physical and sexual abuse, harsh punishments, and dehumanizing treatments have now been exposed, and their devastating impact on Indigenous communities has been disclosed in the traumatic narratives of the survivors, through mechanisms such as the Truth and Reconciliation Commission created in 2007-2008. Negative impacts are rooted in the severing of parental relationships with children who were institutionalized in boarding schools. Children and their parents and families suffered from being denied the opportunity to grow and learn within responsible, loving, and caring parental and family relationships. Though residential school experiences varied, the majority of children suffered traumatic abuses (Aboriginal Healing Foundation, 2005; Fournier \& Crey, 1997; RCAP, 1996). Participants express how dysfunctional ways of relating learned through residential school experiences have been transmitted through generations so that the problem remains unresolved (Younging, Dewar, \& DeGagné, 2009). It is challenging to deal with these multigenerational traumas:

You have to think about that, you know, all that multigenerational stuff. People don't want to go back there. It's hard, hurtful. Look at the residential school? Some people won't even still, they don't want to go back there.

Despite the painful traumas underlying challenging family circumstances, it remains essential to find a way to move toward the teachings of the Great Spirit: 
Social-Relational Understandings of Health and Well-Being from an Indigenous Perspective $\bullet$ Richard B Hovey, Treena Delormier, Alex McComber

Focus on the positive, because that other part is the power of the family and that's the unity and if you don't have that, and you see it now, like the family breakdown is what's tearing us apart right now.

Notwithstanding the challenges inherent in addressing the negative impact of multigenerational traumas on family well-being, there are positive developments. The focus on fixing problems can often overshadow promising changes such as family practices within the community that promote collective well-being:

... But a lot of the young people are doing good things, even if they're young parents, they're doing great with their families and they're being the families that they probably didn't have when they were young. (laugh) So they're doing and role modelling and a lot of them are going back to the longhouse. So, that's what I see, the positivity in the youth that gets, again, not enough air-time.

Young families are recognized for making efforts to create safe and nurturing families, even if that was a dynamic they themselves did not experience while growing up. Traditional teachings are helping these young people learn how to have harmonious family lives through valuing traditional cultural practices. Unfortunately these positive examples seem to be overshadowed by the attention that too often focuses on problems that manifest within the community; these are the issues for which community support and healthcare workers are primarily responsible. The people, especially children and youth, benefit from positive, healthy role models whose experience of overcoming personal traumas demonstrates the tenacity and resiliency of Indigenous people who are expressing their potential to live wholistically healthy lives.

\section{Understanding Interruptions Deeply Rooted in a Colonial Past}

Well, the core emotion is always hurt, no matter where that comes from, but it depends on what area, 'cause if you're talking about as a community, all that stuff comes up. It's not, it's not hurt in a way like, "Oh, you hurt my feelings. I'm so mad at you." It's more like a (laugh), "You frigging tried to kill us."

Underlying the challenges to being well as an individual and a family is the "hurt" harboured individually and collectively at a community level (Struthers et al., 2003). This hurt and the ensuing anger is rooted in the awareness of the violent acts of history committed by the colonizers and their descendants against the Indigenous population. Furthermore, the impact of attempted cultural genocide has affected the unity of the community and the unity of the Haudenosaunee. The pain of one generation is passed on to the next; often it takes the form of hushed-suffering so as not to burden the children and succeeding generations. When hurt is buried deeply and not talked about, everyone related to the sufferer feels and shares the pain, even if they do not know why. This becomes an inherited trauma (Yellow Horse Brave Heart \& DeBruyn, 1998). When unspeakable things happen to a person and that trauma becomes buried deep within his or her soul, the soul is wounded and the body pays the price through manifestations of illnesses, substance abuse, and depression at levels dramatically exceeding those in the external, dominant society (Duran, Duran, Yellow Horse Brave Heart \& HorseDavis, 1998). 
Social-Relational Understandings of Health and Well-Being from an Indigenous Perspective $\bullet$ Richard B Hovey, Treena Delormier, Alex McComber

Ska'nikon:ra entewatste (being of one mind) represents the Haudenosaunee and Kanien'kehá:ka value of working together for collective community benefit. The concept is put into practice through setting aside personal differences in order to engage in honest and informed discussions and so develop an agreed-upon course of action:

Maybe if we were all of one religious mind or train of thought it would be different. But because we have so many different persuasions going on, it sometimes hinders what we do as a community. We're not always the collective.

A return to ska'nikon:ra entewatste as a way of thinking and decision-making would greatly encourage the collaborative processes required to address such serious community issues as diabetes. When there are many divergent perspectives on how a community should conduct itself, advancement can become paralyzed through the community's inability to arrive at a consensus-based response to issues and concerns. Division of thought may create a community of mistrust, which can also stand in the way of working collaboratively. The chronic tension and mistrust among different groups of people in this community represents a colonial inheritance. Unfortunately, if these effects linger over time they can perpetuate an interference with the community's ability to live in harmony:

What, you can never go to each other's longhouse, because what? Because your greatgrandfather told you not to? My family was in that and I know it's all personal issues that divided these people. They make it political and spiritual, religious, only to cover up all that, but it was all personal, the division. And that all comes from hatred. The colonization that was brought to us just kept the infighting going and it still happens. It still happens. And people have to wake up to that fact and, we're not the enemy; ... stop fighting. Focus on the positive.

Trust toward the colonizers gave way to mistrust as their oppression of Indigenous Peoples became evident. This mistrust, internalized over generations, can manifest toward our families and communities (Duran, 2006). Learning to trust one another within the community itself presents challenges as mistrust keeps Indigenous communities off balance and less likely to find a cohesive voice. We recognize that explicit colonization has been internalized and expressed in practices that still hinder the well-being of individuals, families, and the community (Struthers et al., 2003). An alternative voice is needed to challenge the negative effects of internalized colonization (Duran et al., 1998; Poupart, 2003).

\section{Multigenerational traumas.}

From the smallpox plague, religious conversion, colonial wars, residential school experiences, the impact of alcohol and Canadian legislation, to devastation of the environment, the frequency and severity of trauma varies from person to person depending on unique life experiences. We cannot accurately predict how a person's life will be shaped by external events, and the experiences of joy, trauma, comfort, despair, peace, and hopelessness that they bring. Nevertheless, we do know that the cumulative effects of traumas, which span multiple generations, can seriously impede efforts to promote healthy lifestyles (Yellow Horse Brave Heart \& DeBruyn, 1998). 
Social-Relational Understandings of Health and Well-Being from an Indigenous Perspective $•$ Richard B Hovey, Treena Delormier, Alex McComber

\section{Forward Moves}

Participants related current social conditions and relationships that negatively affect wellbeing to the colonization experiences of Indigenous Peoples within the context of the Kanien'kehá:ka and Kahnawà:kehró:non specifically. All of the participants in this study are directly connected to community diabetes-prevention activities or health care. The researchers were led to an understanding that the history of the impact of colonization on individual and community well-being offers a profound source of information and guidance for dealing with the influences of multigenerational trauma (Struthers et al., 2003). In the following quotation, the participant states the importance of viewing diabetes from a wholistic health perspective:

Now, right now ... I think our epidemic, in not only this community but globally aside from diabetes, is mental illness. And I'm going to have to tell you something, that diabetes is part of mental illness because if you were not mentally ill you would not have diabetes. That's a big one isn't it? That's a big one. Sickness, I'm afraid to say, is not about germs and viruses. It's about all of the negative emotions that you harbour. So, you need to go into your good mind, where the Great Spirit dwells.

The global diabetes epidemic is seen as part of the mental illness epidemic, and though sickness is often explained as being caused by disease vectors, other factors such as mental illness (Wieman, 2009), harboured unresolved negative emotions, distress, and relationships play powerful roles as well. Healing requires the wisdom and influence of a sound mind, and awareness of spirit, which offers a means to wholistically address diabetes prevention.

Unresolved negative emotions have their roots in colonization-induced traumas. Reconnecting with traditional healing practices offers a way to resolve and heal historical trauma:

Carrying on the traditions and our ways and our language, and you know, technically, how long has colonization been here? We should have been gone a long time ago. Everything should be dead; we should have no language. But it's growing; it's growing in Kahnawà:ke.

The resilience and strength of the community is evident in surviving a history of attempts to assimilate the Indigenous population into the dominant settler society through the destruction of cultural identity and practices (Kirmayer, Dandeneau, Williamson, Phillips, \& Marshall, 2011). Not only has the community survived, it continues to nurture, enhance, and support Indigenous values, language, traditional culture, and knowledge in order to build strong cultural foundations for future generations. Traditional teachings and knowledge hold promise for wholistically taking care of one's self and working toward well-being on an individual level:

Absolutely. Yeah, healthy mind, healthy body, and in essence, if you have those two, you're going to have a healthy spirit. And I think if there's focus on, if you could focus that one at a time, you'll bring yourself back to a true being, an Onkwehon:we.

At a community or collective level moving forward in a healthy way means to become of one mind, and to collaborate in a spirit of respect. This shared consciousness would promote the 
Social-Relational Understandings of Health and Well-Being from an Indigenous Perspective $\bullet$ Richard B Hovey, Treena Delormier, Alex McComber

positive relationships that are required at the community level in order to align efforts and combine resources around a common vision:

The community would work more collaboratively in every area. So that we're all on the same page, and we all understand each other and we all listen to each other and we all know.

Indigenous communities demonstrate their resilience in being able not only to survive despite colonization-induced traumas, but also to begin the process of rebuilding healthy communities based on traditional teachings and knowledge (Kirmayer et al., 2011). Efforts continue toward a vision of strong families and healthy future generations with a distinct Haudenosaunee and Kanien'kehá:ka cultural identity. Diabetes is a threat to that vision and the changes required to battle diabetes translate into daily trials and tribulations along the way to regaining a physically active lifestyle, having the option to make healthy food choices, and being well as Onkwehon:we. This requires consistency, presence, and solidarity; a community of likeminded people working together in recognition of the tremendous challenges to be faced.

\section{Conclusion}

This research began as an exploration into what Kahnawà:kehró:non believe are the most significant impediments to diabetes prevention and health promotion for enhanced well-being for their community. When we asked participants to reflect on diabetes and diabetes prevention, their greatest concern was the multigenerational trauma created over hundreds of years through acts of colonization, oppression, and assimilation by European colonizers, the Canadian government, and the churches. This trauma has been further exacerbated by government avoidance and denial, the limited disclosures about these events, and the perceived insincerity of the apologies that have been offered for past oppressive acts. When people are forced to live on the margins of their own society they feel dehumanized and fade into the backdrop of the dominant society surrounding them. We found that the interconnection between the socialconditions of culture, language, and epistemologies (as affected by the dominant external societal forces, politics, and laws) and -relational interpersonal interactions (how people relate to themselves, their families, and their community) influenced health and well-being. These powerful influences were and continue to be experienced daily at individual, family, and community levels (Struthers et al., 2003).

This research offered a powerful opportunity to learn from each other's perspectives while consciously addressing the challenges of privilege, judgment, and mistrust. We tried to ensure that there were no unspoken or misinterpreted expectations. We began with an invitation for a conversation to meaningfully and relationally connect with one another. Indigenous perspectives were revealed within this conversation. Understanding began and was enhanced through the -relational, the characteristics of our relationships. The quality of the -relational gave rise to a mutual concern for feelings, fostering the development of trust and understanding. Sensitive and respectful conversations took place, giving time for anxiety and trauma to be worked through and allowing research participants and researchers to find the words to co-create a shared epistemology.

The recognition that diabetes may be symptomatic of oppressive social conditions initiated innovative thinking about how we might re-conceptualize the conditions that influence the well-being of an Indigenous community (Alfred, 2009b; Hart, 2010; Kulnieks et al., 2010; 
Social-Relational Understandings of Health and Well-Being from an Indigenous Perspective $\bullet$ Richard B Hovey, Treena Delormier, Alex McComber

Wilson, 2008). Recognizing that diabetes may be an expression of the social-relational wellbeing of a community has created an understanding that well-being includes dimensions other than the already-established risk factors for diabetes (obesity, inactivity, unhealthy eating habits, and uncontrolled stress); dimensions that are closely related to social-relational circumstances (Dow, 2006; Haskell \& Randall, 2009; Hovey, 2012; Metallic, 2004; Travers, 1995). The Findings from this interpretive research mean that as community health workers, health promotion practitioners, and researchers, we need to continue to explore methods of supporting individual, family, and community relationships to improve wholistic well-being. This requires innovating ways to create social-relational conditions that acknowledge and support the spiritual dimensions of well-being and identity, the concept of Onkwehon:we, the roles and responsibility of families as nurturers of health-promoting relationships, and processes that will heal multigenerational traumas rooted deeply within a history of colonization (Lavallee \& Clearsky, 2006). While this may be a new approach for health promotion within Indigenous communities, it is a shared understanding of what Kahnawakero:non, and by extension, Kanien'keha:ka Haudenosaunee and Indigenous people believe is required to prevent type 2 diabetes, and move toward promoting Onkwehon:we in Kahnawà:ke.

\section{References}

Aboriginal Healing Foundation. (2005). Reclaiming connections: Understanding residential school trauma among Aboriginal People. Ottawa, ON: Author.

Adelson, N. (2005). The embodiment of inequity: Health disparities in Aboriginal Canada. Canadian Journal of Public Health, 96(S2), 45-61. Retrieved from http://proquest.umi.com/pqdweb?did=869710491\&sid=2\&Fmt=4\&clientId=10843\&RQT $=309 \&$ VName $=$ PQD

Alfred, G. T. (2005). Wasase - Indigenous pathways of action and freedom. Peterborough, ON: Broadview Press.

Alfred, G. T. (2009a). Restitution is the real pathway to justice for Indigenous Peoples response, responsibility and renewal: Canada's truth and reconciliation journey. Ottawa, ON: Aboriginal Healing Foundation.

Alfred, G. T. (2009b). Colonialism and state dependency. Journal of Aboriginal Health, 5(2), 4260.

Binding, L. L., \& Tapp, D. M. (2008). Human understanding in dialogue: Gadamer's recovery of the genuine. Nursing Philosophy, 9(2), 121-130. doi:10.1111/j.1466-769x.2007.00338.x

Bisset, S., Cargo, M., Delormier, T., Macaulay, A. C., \& Potvin, L. (2004). Legitimizing diabetes as a community health issue: A case analysis of an Aboriginal community in Canada. Health Promotion International, 19, 317-26. doi:10.1093/heapro/dah305

Blanchard, D. (1980). Seven Generations. Kahnawake Mohawk Territory, QC: Center for Curriculum Development, Kahnawake Survival School. 
Social-Relational Understandings of Health and Well-Being from an Indigenous Perspective $\cdot$ Richard B Hovey, Treena Delormier, Alex McComber

Brant-Castellano, M. (2004). Ethics of Aboriginal research. Journal of Aboriginal Health, 1(1), 98-114.

Brass, G. (2009). Respecting the medicines: Narrating an Aboriginal identity. In L. Kirmayer, G. Valaskakis (Eds.), Healing traditions: The mental health of Aboriginal Peoples in Canada (pp. 355-380). Vancouver, BC: UBC Press.

Davey, N. (2006). Unquiet understanding: Gadamer's philosophical hermeneutics. New York: SUNY Press.

Dow, S. A. (2006). Beyond sweet blood: Perception of type 2 Diabetes in Kahnawà:ke. (Unpublished master's thesis). Concordia University, Montreal, QC.

Duran, E. (2006). Healing the soul wound: Counseling with American Indians and other native peoples: Multicultural Foundations of Psychology and Counseling. New York, NY: Teachers College Press.

Duran, E., Duran, B., Yellow Horse Brave Heart, M., \& Horse-Davis, S. Y. (1998). Healing the American Indian soul wound. In Y. Danieli (Ed.), International handbook of multigenerational legacies of trauma (pp. 341-354). New York, NY: Plenum Press. doi:10.1007/978-1-4757-5567-1_22

Ermine, W. (2007). The ethical space of engagement. Indigenous Law Journal, 6(1), 193-204.

Ermine, W., Sinclair, R., \& Jeffery, B. (2004). The ethics of research involving Indigenous peoples. Report of the Indigenous peoples' health research centre to the interagency advisory panel on research ethics (PRE). Saskatoon, SK: Indigenous Peoples' Health Research Center.

Fournier, S. \& Crey, E. (1997). Stolen from our embrace: The abduction of First Nations children and the restoration of Aboriginal communities. Vancouver, BC: Douglas and McIntyre.

Gadamer, H- G. (1976). Philosophical hermeneutics (D. E. Linge, Trans.). Los Angeles, CA: University of California Press.

Gadamer, H- G. (1989). Truth and method (2 ${ }^{\text {nd }}$ ed.). (J. Weinsheimer \& D. G. Marshall, Trans.). New York, NY: Continuum.

Gadamer, H- G. (1992). Hans-Georg Gadamer on education, poetry and history. (D. Misgeld \& G. Nicholson, Eds., L. Schmidt and M. Reuss, Trans.). Albany, NY: State University of New York Press.

Gadamer, H- G. (1996). The enigma of health: The art of healing in a scientific age. (J. Gaiger \& N. Walker, Trans.). Stanford, CA: Stanford University Press.

Grondin, J. (2003). Philosophy of Gadamer (K. Plant, Trans) (Vol. 3). Montreal, QC: McGillQueen's Press-MQUP. doi:10.4324/9781315710617 
Social-Relational Understandings of Health and Well-Being from an Indigenous Perspective $\bullet$ Richard B Hovey, Treena Delormier, Alex McComber

Hart, M., A. (2010) Indigenous worldviews, knowledge, and research: The Development of an Indigenous research paradigm. Journal of Indigenous Voices in Social Work, 1(1), 1 -16. Retrieved from http://scholarspace.manoa.hawaii.edu/bitstream/handle/10125/15117/v1i1_04hart.pdf?seq uence $=1$

Haskell, L., \& Randall, M. (2009). Disrupted attachments: A social context complex trauma framework and the lives of Aboriginal Peoples in Canada. Journal of Aboriginal Health, $5(3), 6-47$.

Horn-Miller, K. (2003). The emergence of the Mohawk warrior flag: A symbol of Indigenous unification and impetus to assertion of identity and rights commencing in the Kanienkehaka community of Kahnawà:ke. (Unpublished master's thesis). Concordia University, Montreal, QC.

Horn, O. K., Jacobs-Whyte, H., Ing, A., Bruegl, A., Paradis, G., \& Macaulay. A., C. (2007). Incidence and prevalence of type 2 diabetes in the First Nation of Kahnawa:ke, Quebec, Canada, 1986-2003. Canadian Journal of Public health, 98(6), 438-443.

Hovey, R. (2012). Assessment in health promotion: Deconstruction and metaphoric considerations in a nutshell. In G. D. Gilmore (Ed.), Needs and capacity assessment strategies for health education and health promotion (4th ed.), (pp. 333-344). Sudbury, MA: Jones and Bartlett.

Hovey, R., \& Craig, R. (2011) Understanding the relational aspects of learning with, from, and about the other. Nursing Philosophy, 12, 262-270. doi:10.1111/j.1466-769x.2011.00491.x

Hovey, R., Dvorak, M., Hatlie, M., Burton, T., Padilla, J., Worsham, S., \& Morck, A. (2011). Patient safety: A consumer's perspective. Qualitative Health Research, 21(5), 662-672. doi:10.1177/1049732311399779

Hovey, R., \& Paul, J. (2007). Healing, the patient narrative-story and the medical practitioner: A relationship to enhance care for the chronically ill patient. International Journal of Qualitative Methods, 6(4), 53-66.

Hovey, R. B. (2006). What does it mean to live with osteoporosis? (Unpublished doctoral dissertation). University of Calgary, Calgary, AB.

Hovey, R.B. \& Amir, N. (2013). The hermeneutics of suffering: Researching trauma. The International Journal of Person Centred Medicine. 3(2), 160-169.

Kahnawà:ke Schools Diabetes Prevention Project (KSDPP). (2007). Code of Research Ethics. Retrieved from http://ksdpp.org/media/ksdpp_code_of_research_ethics2007.pdf

King, J. T. (2007). The value of water and the meaning of water law for the Native Americans known as the Haudenosaunee. Cornell Journal of Law and Public Policy, 16(3), 450-470. 
Social-Relational Understandings of Health and Well-Being from an Indigenous Perspective $\bullet$ Richard B Hovey, Treena Delormier, Alex McComber

King, M., Smith, A., \& Gracey, M. (2009). Indigenous health part 2: The underlying causes of the health gap. Lancet, 374, 76-85. doi:10.1016/s0140-6736(09)60827-8

Kirmayer, L., Dandeneau, S., Williamson, K., Phillips, M., \& Marshall, E. (2011). Rethinking resilience from Indigenous perspectives. The Canadian Journal of Psychiatry. 56(2), 8491.

Kirmayer, L., Tait, C., \& Simpson, C. (2009). The mental health of Aboriginal peoples in Canada: Transformations of identity and community. In L. Kirmayer \& G. Valaskakis (Eds.), Healing traditions: The mental health of Aboriginal peoples in Canada (pp. 3-35). Vancouver, BC: UBC Press.

Kirmayer, L., \& Valaskakis, G. (2009). Healing traditions: The mental health of Aboriginal Peoples in Canada. Vancouver, BC: UBC Press.

Kulnieks, A., Longboat, D. R., \& Young, K. (2010). Re-Indigenizing curriculum: An ecohermeneutic approach to learning. AlterNative: An International Journal of Indigenous Peoples, 6(1), 15-24. Retrieved from http://www.alternative.ac.nz/journal/volume6issue1/article/re-indigenizing-curriculum-eco-hermeneutic-approach-learning

Kovach, M. (2009). Indigenous methodologies: Characteristics, conversations, and contexts. Toronto, ON: University of Toronto Press.

Lavallee, B., \& Clearsky, L. (2006). 'From woundedness to resilience': A critical review from an Aboriginal perspective. The Journal of Aboriginal Health, 3(1), 4-6.

Long, K. A. (2001). A reality orientated approach to interdisciplinary work. Journal of Professional Nursing, 17(60), 278-282. doi:10.1053/jpnu.2001.28183

Macaulay, A. C., Commanda, L. E., Freeman, W. I., Gibson, N., McCabe, M. L., Robbins, C. M.,...Twohig, P.L. (1999). Participatory research maximises community and lay involvement. British Medical Journal, 319, 774-778.

Macaulay, A. C., Montour, L. T., \& Adelson, N. (1988). Prevalence of diabetic and atherosclerotic complications among Mohawk Indians of Kahnawà:ke, P.Q. Canadian Medical Association Journal, 139, 221-224.

Macaulay, A. C., Paradis, G., Cross, E. J., Saad-Haddad, C., McComber, A., Desrosiers, S., Rivard, M. (1997). The Kahnawà:ke schools diabetes prevention project: Intervention, evaluation, and baseline results of a diabetes primary prevention program with a native community in Canada. Preventive Medicine, 26, 779-790. doi:10.1006/pmed.1997.0241

McGuire, P. D. (2010). Resilience and Indigenous ways of knowing. Pimatisiwin: A Journal of Aboriginal and Indigenous Community Health, 8(2), 117-131.

Metallic, J. E. (2004). Understanding diabetes in a Cree community: A qualitative study. (Unpublished master's thesis). McGill University, Montreal, QC. 
Social-Relational Understandings of Health and Well-Being from an Indigenous Perspective $\bullet$ Richard B Hovey, Treena Delormier, Alex McComber

Montour, L., \& Macaulay, A. (1985). High prevalence rates of diabetes mellitus and hypertension on a North American Indian reserve. Canadian Medical Association Journal, 132, 1111-1112.

Milloy, J. S. (1999). A national crime: The Canadian government and the residential school system 1879-1986. Winnipeg, MB: University of Winnipeg Press.

Mundel, E., \& Chapman, G. E. (2010). A decolonizing approach to health promotion in Canada: The case of the urban Aboriginal community kitchen garden project. Health Promotion International, 25(2), 166-173. doi:10.1093/heapro/daq016

Phillips, M. (2010). Understanding resilience through revitalizing traditional ways of healing in a Kanien 'kehá:ka community. (Unpublished master's thesis). Concordia University, Montreal, QC.

Poupart, L. M. (2003). The familiar face of genocide: Internalized oppression among American Indians. Hypatia, 18(2) 86-102. doi:10.1111/j.1527-2001.2003.tb00803.x

Pringle, D., Levitt, C., Horsburgh, M. E., Wilson, R., Whittaker, M. K. (2000). Interdisciplinary collaboration and primary health care reform: Statement from the Ontario chairs of family medicine and the council of Ontario university programs in nursing. Canadian Family Physician, 46, 763-767.

Royal Commission on Aboriginal Peoples. (RACP) (1996). Report of the Royal Commission on Aboriginal Peoples. Ottawa, ON: The Royal Commission on Aboriginal Peoples.

Smith, L.T. (1999). Decolonizing methodologies: Research and Indigenous peoples. London, UK: Zed Books.

Struthers, R., Schanche Hodge, F., Geishirt-Cantrell, B. \& De Cora, L. (2003). Participant experiences of talking circles on type 2 diabetes in two northern plains American Indian tribes. International Journal of Qualitative Health Research, 13(8), 1094-1115. doi:10.1177/1049732303256357

Thomas, C. (2003). Developing the social-relational in the social model of disability: A theoretical agenda. In C. Barnes (Ed.), The social model of disability: Theory and research (pp. 32-47). Leeds, UK: The Disability Press.

Thomas, C. (2004). Rescuing a social relational understanding of disability. Scandinavian Journal of Disability Research, 6(1), 22 -36. doi:10.1080/15017410409512637

Travers, K. D. (1995). Using qualitative research to understand the sociocultural origins of diabetes among Cape Breton Mi'kmaq. Chronic Diseases in Canada, 16(4), 140 - 143.

Wieman, C. (2009). Six nations mental health services: A model of care for Aboriginal communities. In L. Kirmayer \& G. Valaskakis (Eds.), Healing traditions: The mental health of Aboriginal peoples in Canada (pp. 401-418). Vancouver, BC: UBC Press. 
Social-Relational Understandings of Health and Well-Being from an Indigenous Perspective $\bullet$ Richard B Hovey, Treena Delormier, Alex McComber

West, R., Stewart, L., Foster, K \& Usher, K. (2012). Through a critical lens: Indigenist research and the Dadirri Method. International Journal of Qualitative Health Research. 22(11), 1582-1590. doi:10.1177/1049732312457596

Willows, N. D., Hanley, A. J. G., \& Delormier, T. (2012). A socioecological framework to understand weight-related issues in Aboriginal children in Canada. Applied Physiology Nutrition and Metabolism Journal, 37(1), 1-13. doi:10.1139/h11-128

Wilson, S. (2008). Research is ceremony: Indigenous research methods. Halifax, NS: Fernwood.

Wulff, D. (2010). Unquestioned answers: A review of research is ceremony: Indigenous research methods. The Qualitative Report, 15(5), 1290-1295. Retrieved from http://www.nova.edu/ssss/QR/QR15-5/wilson.pdf.

Yellow Horse Brave Heart, M., \& DeBruyn, L. M. (1998). The American Indian holocaust: Healing historical unresolved grief. American Indian and Alaska Native Mental Health Research, 8(2), 60-82. doi: 10.5820/aian.0802.1998.60

Younging, G., Dewar, J., \& DeGagne, M. (2009). Response, responsibility, and renewal: Canada's truth and reconciliation journey. Ottawa, ON: Aboriginal Healing Foundation. 